\title{
Professional decision making and women offenders: Containing the chaos?
}

\author{
Monica Barry, University of Strathclyde \\ Gill Mclvor, University of Stirling
}

\begin{abstract}
This article draws on the findings from research undertaken in south-east Scotland in 2008 which sought to identify the characteristics of female offenders and to document the views of policy makers and practitioners regarding the experiences of women involved in the Scottish criminal justice system. Despite Scotland having retained a stronger 'welfare' focus than elsewhere in the UK (e.g. McAra, 2008), this is not reflected in the treatment of women who offend, with the rate of female imprisonment having almost doubled in the last ten years and community based disposals falling short of a welfare-oriented system. This article explores why the treatment that women offenders receive in the criminal justice system may be harsh and disproportionate both in relation to their offending and in relation to the treatment of men. It is argued that interventions with women need to be initiated earlier in their cycle of offending and at an earlier stage in the criminal justice process but also that the wide-ranging health, welfare, financial and behavioural needs of women who offend cannot be met solely within an increasingly risk-averse and punitive criminal justice environment.
\end{abstract}

\section{Introduction}

Many Western jurisdictions have witnessed an unprecedented rise in their prison populations in recent years, resulting in a growing political concern that custody rates need to decrease and community-based alternative measures be expanded. Whilst women constitute only a minority of the prison population, their imprisonment is increasing at a greater rate than that of men (Mclvor, 2007), even though their offending is less serious and less frequent.

In England and Wales between 1996 and 2006, there was a 94 per cent increase in women's imprisonment, compared with a 38 per cent increase for men's (Ministry of Justice/NOMS, 2008). In Scotland, the number of adult female receptions under direct sentence has increased from 430 in 2001/2 to 829 in 2007/8. This represents an increase of 93 per cent compared with a 29 per cent increase in the same period in the number of directly sentenced adult men (Scottish Government, 2008a). The use of custody with women appears overall to be disproportionate to their offending behaviour and to reflect harsher and more punitive approaches to the sentencing of female offenders (Hedderman, 2004).

Although the use of community sanctions has increased in Scotland for women, this increase has been in the higher tariff disposals of probation and community service at the expense of the use of fines, which has decreased. For example, between 1997 and 2007 the number of community sentences imposed on women in Scotland increased from 1740 to 2693 but the number of women fined decreased from 14,005 to 12,501 over the same period (Scottish Government, 2008b). Moreover, sheriffs are more likely in the case of female offenders to attach additional requirements to probation orders of drug treatment or medical/psychiatric treatment (Scottish Executive, 2008c). Such requirements, if not adhered to, are likely to result in breach proceedings being initiated with the resultant likelihood of escalation through the system.

Whilst there is evidence that in certain respects men and women have similar 'criminogenic needs', how these needs intersect with criminal behaviour may differ 
in important ways (Mclvor, 2007). However, promoting the use of effective and appropriate community sanctions for female offenders presents particular challenges. There is a growing recognition of the need for gender-appropriate provision because interventions and services developed for male offenders (and based on an understanding of male offending) are unlikely to effectively meet female offenders' needs. For this reason, Sheehan et al. (2007) argue strongly for alternative gender-specific responses to women offenders which might encourage a reduction in the use of imprisonment for this vulnerable group. Such responses need to offer support not only to reduce women's involvement in offending, but also to address their underlying problems such as low self-esteem, mental and physical health problems, limited access to social and economic capital, and limited educational and employment opportunities.

Whereas it appears that men tend to respond to interventions which focus directly on offending behaviour, there is evidence that women who offend need practical and emotional support for a wider range of problems during periods of crisis (Mclvor, 2008). In a study of probation with female offenders in Scotland, Mclvor found that practitioners recognized a need for interventions with women to be more informal, less structured and more focused upon issues other than offending behaviour. Community sanctions are, it seems, more likely to work effectively with women if they are flexible in their implementation, not least because women tend to have a greater propensity than men to breach orders as a result of non-compliance rather than further offending (Scottish Government, 2007).

This article firstly describes the profile of women offenders in one Community Justice Authority ${ }^{1}$ in Scotland before looking in greater depth at how decisions by professionals may impact on the effectiveness of work to address women's underlying problems.

\section{A profile of women offenders in Scotland}

This article is based on a study (Barry and Mclvor, 2008) of the characteristics and needs of women offenders in Lothian and Borders Community Justice Authority (in south-east Scotland) which constitutes some 17 per cent of the overall Scottish population. The need for the research was prompted by The National Strategy for the Management of Offenders in Scotland and the Management of Offenders etc. (Scotland) Act 2005, both of which gave priority to improving services for women offenders across all the Community Justice Authorities. The first element of the study comprised an audit of all female offenders entering, currently in, and leaving the criminal justice system from April 2007 - March 2008, with relevant data (including demographic information, offence histories and details of risk and needs assessments), collected from nine statutory and four voluntary agencies. The second element of the research involved semi-structured interviews with 22 key stakeholders, including policy makers, practitioners and managers from the statutory (16) and voluntary sector (6). In addition, a total of 27 social work case fi les were also examined in depth in order to gain a clearer picture of the types of interventions offered to women offenders in the area.

Data from the police indicated that in the year ending March 2008, nearly 12,000 crimes were recorded as having been committed by women in Lothian and Borders while data from the Scottish Courts Service indicated that over 3000 cases involving women had gone to court. During the same period over 1000 cases involving women were referred to social work for either social enquiry reports pending sentence, or for social work supervision (having been diverted by the procurator fiscal or sentenced by the court). Analysis of disposals imposed in 573 cases revealed that 68 women (12 per cent) were given custodial sentences, but the 
main disposal by the courts was probation, with 257 women ( 45 per cent of those sentenced) being given probation with or without additional requirements ( 26 and 19 per cent respectively). The main offences for which women were given probation orders were theft, fraud, breach of the peace and minor assaults, and the main offences which resulted in custody were shoplifting, assault, public order offences and drug offences. Two-thirds of women who were imprisoned $(66 \%)$ received a custodial sentence of three months and under (Barry and Mclvor, 2008).

The majority of the women referred to social work for reports or supervision were in the age range 26-33, although some 20 per cent were under 21. In Edinburgh city, where details of living arrangements were most likely to have been recorded in social work databases, nearly half of the women were identified as having their own tenancy and a quarter were living with relatives. Whilst a quarter of women had their children living with them, nearly as many had children living elsewhere (which suggests they were being cared for by the local authority or by relatives). Eighty-seven per cent of the women were unemployed. According to the case file analysis, the main issues for women offenders identified by social workers included mental health problems, alcohol and drug problems and past or current abuse (including self-harm).

Whilst such issues for women offenders are no doubt well-known amongst academics, policy makers and practitioners alike in the criminal justice field, current decision making about whether or not to prosecute and how to sentence women offenders is influenced as much by the need for public protection, the availability of community-based disposals, practitioner risk assessments and resource limitations. The following section outlines the issues for professionals, namely prosecutors, sentencers and practitioners, when making decisions about women offenders in Lothian and Borders.

\section{Prosecutor decision making}

The police in Scotland have even less discretion to deal informally with alleged offending than their counterparts in England and Wales (Morgan, forthcoming). Whilst they may wish to offer welfare support to women who come to their attention because of an alleged offence - and indeed do offer informal advice and onward referral once women are in police custody - their role is limited to focusing on the facts of an offence rather than the circumstances of the offender when reporting incidents to the procurator fiscal. It is therefore at the stage of marking cases for prosecution that there is greater discretion on the part of criminal justice professionals to direct women away from the criminal justice process and towards potential sources of support. Harsher responses to women's offending could thus arguably be seen to start at the point of prosecutor decision making, since it is procurators fiscal in Scotland who have the option to either take no further action on a case, to divert the alleged offender from prosecution, or to proceed to prosecution, and such decisions are informed by a range of factors including the public interest. It was not possible in this study to access statistics on the numbers of women dealt with in these three ways, though national data indicate that in 2006/7 13 per cent of reports to the procurator fiscal resulted in no proceedings, 22 per cent resulted in the case being diverted from prosecution and 65 per cent resulted in prosecution (Scottish Government, 2008b).

Although prosecutors in Scotland are able to deal with alleged offenders other than by prosecution, the introduction of summary justice reforms in March 2008 has given the Crown Office and Procurator Fiscal Service (COPFS) greater scope for diverting alleged offenders away from the Criminal Justice system through the use of direct measures such as fiscal fines and diversion to social work and other 
service agencies. Despite the majority of cases reported to the procurator fiscal involving men, the majority of alleged offenders diverted from prosecution to social work services are women: 53 per cent in 2007-8 (Scottish Government, 2008c). Social work diversion has, moreover, been most used in Lothian and Borders, which accounts for 44 per cent of all cases in Scotland diverted in this way but comprises less than one-fifth of the overall offender population (Lothian and Borders CJA, 2008). It would therefore seem that nationally there are widely varying uses made of diversion from prosecution, with scope for greater use to be made of this option with women for whom prosecution is not deemed necessary in the public interest (see Conclusions below).

Irrespective of the significant use of diversion in Lothian and Borders during the period under study, the majority of cases of women offenders proceeded to prosecution, which is where sentencer decision making has arguably the greatest influence on women's often repeat journeys through the criminal justice system.

\section{Sentencer decision making}

Just as the use of diversion from prosecution appears to vary across Scotland, there was evidence from this study of variations in the sentencing of women across courts. For example, in comparison with other courts in the sheriffdom, Edinburgh sheriff court was more likely to use imprisonment and less likely to use probation for women. While these differences may in part reflect differences in the offending patterns and histories of women appearing before different courts, it may also be the case that sentencers' decision making is influenced by the perceived availability and effectiveness of particular disposals and by varying practices amongst the writers of social enquiry reports (SERs) (the equivalent to Pre Sentence Reports in England and Wales: see section on Practitioner decision making below).

Although it was beyond the scope of this study to elicit the views of sentencers themselves about their perceptions of the issues involved in sentencing women, other professionals expressed views about whether and how sentencer decision making took account of the assessed needs of women. The vast majority of respondents felt that sheriffs, when sentencing women, did not always make decisions that were based on women's needs as identified in SERs, although a minority of respondents felt that sheriffs treated women no differently than men in that respect. There was, however, a majority view amongst professionals that women were more likely than men to be 'up-tariffed' by being given harsher sentences that were disproportionate to the offence and in comparison to the treatment of male offenders:

[W]omen will be sentenced to [prison], whereas if it was a male that had done that, they would get a community disposal. [Sheriffs] seems to be a lot harder on women offenders.

Corston (2007) argues that imprisoning women can have long-term deleterious effects on women and their families, and that sending a woman to prison when she has established links with caring agencies in the community can rapidly unravel and undermine such work. Prison sentences were deemed by professionals in this study to be inappropriate for all but a minority of serious or violent female offenders, not least because short prison sentences could exacerbate a woman's already fragile situation in the community:

Sending a mother with three kids to prison for three months in my eyes does more harm than good for her, you know. It's breaking up the family, it's maybe having to put the children into care, she's maybe losing her home, and the work that we can do with her in that time is very, very limited, so it serves no purpose whatsoever. 
Several professional respondents felt that sheriffs may consider prison to be a safer option for some women (from the point of view of public as well as personal protection) or that prison might give women with drug problems a period of 'respite' to be able to address these problems:

I do think that [sheriffs will] use Cornton Vale ${ }^{2}$ to get them a health service ... sheriffs see women as quite vulnerable and maybe requiring help and they do accept that it's very difficult for women to access services within the community.

Indeed, it was estimated by respondents that over 95 per cent of women in Cornton Vale Prison had addiction problems. Moreover, the perceived propensity of some sentencers to use imprisonment as a means of enabling women to access help with drug problems was believed by professionals to be compounded by sheriffs' lack of knowledge of, or lack of confidence in, community-based alternatives. As one respondent suggested:

I've certainly had experience of a sheriff putting a woman to custody with the very clear statement in court at the point of sentencing, saying ... 'the only reason you're going to custody today is because adequate facilities don't exist for you within the community'.

There was some scepticism, notably amongst social work professionals, about whether sheriffs understood the philosophy behind community-based interventions, not least with women offenders. Whilst community service is also intended to function as a high-tariff disposal (and is, indeed, legislated to serve as an alternative to custody), it was used in Lothian and Borders relatively infrequently for women (and less frequently than custody). However, there is evidence that in Scotland women are more likely to be given a community service order at an earlier point than men in their involvement with the criminal justice system (Mclvor, 1998; Mclvor and Barry, 1998), thus putting them at increased risk of imprisonment should they fail to adhere to the terms of the order.

Some sheriffs were thought to use probation inappropriately by imposing orders as a welfare option for women who may be at low risk of re-offending or by making orders that were longer than either the offence or the circumstances of the offender would justify. Social workers reportedly often found it difficult to manage lengthy probation orders imposed on women with little or no history of, or inclination towards, persistent offending, and they often attempted to discourage their imposition in social enquiry reports.

Social workers who supervised such probation orders appeared to struggle to find constructive and justifiable interventions for women, not least if the sentence imposed did not accord with the advice on the suitability of different disposals that had been offered in social enquiry reports. It was therefore of some concern that during the year under study some 34 per cent of probation orders imposed on women in Lothian and Borders were breached. Although comparable data were not available for men, national statistics indicate that in 2007/8 25.4 per cent of terminations of probation orders on women were as a result of breach, compared to 28.9 per cent of terminations of orders imposed on men. However, that year of noncompliance (17.2 per cent compared with 15.8 per cent) while men were more likely than women to be breached for a further offence (10.9 per cent compared with 7.1 per cent) (Scottish Executive, 2008c).

This seeming incompatibility between a social worker's suggested course of action 
(based on a risk/needs assessment) and the subsequent sentence imposed, coupled with limited resources in the community which were appropriate to women's needs, also played out in different ways by different practitioners, as the following section highlights.

\section{Practitioner decision making}

In Scotland, as elsewhere in the UK, decision making by practitioners is increasingly based on principles of risk minimization, accountability and 'what works' as enshrined in National Standards and associated guidance, with a clear focus on reducing reoffending and public protection rather than addressing needs and providing support. Practitioners in this study were quick to acknowledge the tensions arising from such a focus, not least with vulnerable women leading often chaotic lives.

\section{Risk assessments}

All the social work departments in Lothian and Borders tend to use the Level of Service Inventory - Revised (LSI-R) to assess risk of re-offending and the Risk Assessment Guidance Framework (RAGF) to assess risk of harm. It was generally felt by respondents in this study, as elsewhere (see, for example, Mclvor and Kemshall, 2002; Maurutto and Hannah-Moffat, 2006), that risk assessment tools such as these are not appropriate for women offenders, not least because their development is based predominantly on populations of men. Of particular concern was the perception that, when applied to women, these assessment tools tended to overpredict women's risk of re-offending whilst failing adequately to identify health and other needs that are of particular relevance to women. Indeed, analysis of social work data in the present study indicated that whereas a relatively high proportion of women were assessed as at a low risk of re-offending, an equally high proportion were assessed as at least a moderate risk. Even where 'needs' were identified through the use of risk assessment tools it was not clear whether and how they related to women's offending.

Equally, other women in this study were ranked as having a high or very high risk of re-offending because of their unemployment, low educational achievement, past convictions (often amassed in their youth) and mental health problems. Such actuarial calculations may not only prompt often inappropriate or harsh responses from the bench, but they also deny the possibility either that a woman is in the process of desistance from crime or that offending is a symptom rather than a cause of other, more deep-rooted problems in their lives. Basing the likelihood of re-offending on factors such as mental health, unemployment and relationship difficulties is therefore somewhat missing the point unless it can also be established that these 'risk factors' may actually prompt people to offend. Arguably a focus on 'needs' which stabilize a lifestyle, rather than on offending which results from that lifestyle, may better inform both sentencer and practitioner decision making.

Not only might risk assessments up-tariff women but also they are open to wide variation depending on the assessor. As has been found in other studies of risk assessment in social work (see, for example, Barry, 2007a), different social workers will assess differently depending on their age, length of service and experience in the field, and some may prefer to use their discretion or professional judgement more than actuarial methods. Furthermore while the process and outcome of risk assessments may vary within and between statutory agencies, voluntary organizations involved with women offenders do not necessarily assess their clients in terms of risk of reoffending or risk of harm but, rather, according to whether there is any risk to staff working with that individual or, as in the case of health professionals, to identify and prioritize forms of treatment. Risk assessments are standardised tools 
which do not take into account the availability or appropriateness of interventions or services for women, and yet such assessments form the basis on which the need for and access to interventions is determined.

\section{Interventions}

There is an expectation put on practitioners by policy directives that interventions with offenders should remain predominantly offence-focused. This creates a tension for practitioners, particularly with respect to intervening with female offenders. In trying to alleviate that tension, workers suggested that they may either neglect to address welfare needs altogether or attempt to offer a welfare service 'on the back of' addressing offending behaviour'. Equally, the different needs and circumstances of female offenders compared with men often meant that available interventions were inappropriate for many women and enforcement criteria too rigid. Some of the challenges arising from these anomalies are raised below in respect of community-based interventions, the timing of sentences imposed and enforcement criteria.

\section{Probation}

Social workers in this study suggested that probation might offer access to a package of welfare measures which might not otherwise be available to women who needed support rather than punishment per se (e.g. through fines or community service). Balancing a woman's needs for assistance and support against the risk of up-tariffing them was reported to represent a constant dilemma for practitioners in the absence of alternative 'welfare-oriented' disposals. Practitioners were also alert to the fact that some women had a poor image of probation based on previous experiences of social work involvement (either through previous episodes of supervision or through social worker involvement in relation to child care issues) and may not therefore be positively disposed to accept any offers of support made available.

Where probation group work programmes were available for women, it was not uncommon for women to be repeat participants on such programmes during consecutive probation orders, because of a lack of alternative interventions. On the other hand, where group work programmes were not available, social workers suggested that they may have neither the time nor the resources to engage meaningfully with female probation clients on a one-to-one basis. However, clients may also decline one-to-one supervision if they do not feel the need for support per se:

[W] here there was a probation order imposed, l've had women saying, you know, I don't mind doing community service but I really don't want to come and meet with you, you know. There's nothing I need to talk to you about, there's nothing we need to look at. l'll do my community service, l'll get the days done, and that's my punishment. ... She had defrauded social security and it was loads of money. Another woman, she had actually taken money from a relative ... [and] they were both saying to me very clearly, you know, 'you're a nice person, we like chatting to you, but....

\section{Community Service}

Community Service placements were seen by respondents to be designed very much with men in mind, often requiring strenuous physical work in the environment and long hours. Many women were thought by practitioners often to struggle with the conditions imposed by such placements, not least in terms of child care arrangements whilst they are performing such work (see also Mclvor, 2004). Whilst organizing child care facilities (such as registered child minders paid for by the Criminal Justice Social Work Department) is the responsibility of the social work department, women on community service were thought by practitioners to often be wary of such 
arrangements, not least because of past experiences with Children and Families social workers, and yet they may not readily have access to childminders through their own social networks. Practitioners also reported that there may be few or no female supervisors available to oversee community service placements for women who may be reluctant to be supervised by a man and that they had limited scope to match women to placements which are appropriate to their capabilities and interests. Equally, some women may be inappropriate for certain community service placements because of the nature of their offending (for example, women who have been convicted of offences involving dishonesty may be prevented from working with vulnerable people or as shop assistants).

\section{The length of sentence}

Within the prison context, the ability for women's needs to be addressed is dictated to a significant extent by the length of sentence imposed. For women with drug problems, it was suggested by practitioners that the minimum length of sentence which would enable constructive work to be undertaken would be 18 months, of which only nine would be served in prison. Three months would be required to stabilize and engage the woman and four to six months would be required for them to participate in an appropriate group work programme. However, as previously indicated, 66 per cent of all custodial sentences in 2007/08 in Lothian and Borders were for three months and under (with a maximum of six weeks normally served in prison) leaving little time for meaningful engagement with women while they were serving their sentences.

The timing of probation and community service was reported by practitioners as also posing difficulties for workers and clients alike. Probation orders varied considerably in length between courts. Whereas a six month probation order might appear appropriate for a low-tariff, low-need offender, longer orders of up to three years were not uncommon in Lothian and Borders. This not only challenged workers to hold the motivation of the client over an extended period of time but also increased the risk of non-compliance resulting in breach. Given the limited availability of appropriate community service placements for women mentioned earlier, practitioners in Lothian and Borders also found it difficult on occasion to arrange placements and complete orders within the timescale laid down by the court or the accompanying probation order.

\section{Enforcement criteria}

The tendency to be 'gender neutral' within the criminal justice system is perhaps reflected most damagingly in the enforcement of community-based court orders. As previously indicated, 34 per cent of probation orders made in respect of women probationers were revoked during the year under study in Lothian and Borders as a result of breach (in almost all cases as a result of failure to attend appointments rather than because of reoffending). It was often felt by professionals that women required more patience, more tolerance, and more time to resolve other issues in their lives, and that greater discretion was needed by workers when such women failed to attend appointments. The implications of an early breach could, it was suggested, prove devastating to a woman in crisis, not least where the consequence might be a custodial sentence. Indeed, the Corston Report argues for 'a radical new approach, treating women both holistically and individually - a woman-centred approach' which allows for greater flexibility in responses to compliance and breach (Corston, 2007: 2):

[B]reaches of community orders must be made more fl exible as a matter of urgency ... there needs to be more tolerance for women who fail to meet appointments because of their domestic responsibilities and their underlying anxieties (Corston, 
2007: 8-9).

Because women tend to offend for reasons related more to 'necessity' than 'choice' (Barry, 2007b; Home Office, 2004), and because their reactions to interventions are different to those of men, it would seem appropriate - in the interests of both reducing reoffending and enhancing women's reintegration - for practitioners to have greater flexibility in dealing with instances of non-compliance by female offenders.

\section{Multi-agency working}

Multiple needs require multiple interventions, but currently in Scotland services for female offenders are largely accessed through the criminal justice system meaning that the focus tends towards punishment rather than welfare. Moreover, existing services tend to be dispersed across communities placing additional strains on women who are required to keep numerous different appointments while juggling child care and other commitments, thus increasing the possibility of non-compliance and breach. Research has shown that women learn differently, think differently and engage differently to men (for example, women learn better in connective and collaborative settings rather than in distinctive and competitive settings) and that women-only environments which are accessible, non-stigmatizing and non-authoritarian often facilitate their successful engagement (Gelsthorpe and Mclvor, 2007). The development in England and Wales of women's centres - commonly known as 'one stop shops' - have been argued to hold some promise as a more effective approach to dealing with female offenders' diverse and often complex needs (Ministry of Justice/NOMS, 2008).

The present research supports the development of similar provision in Scotland, enabling women to access services and supports in a convenient, non-stigmatizing and easily accessible location. Building upon the experiences of the innovative 218 Centre in Glasgow (Loucks et al., 2006; Malloch et al., 2008), provision such as this would allow professionals from different agencies to work with clients at a centralized location and would facilitate improved inter-agency communication and collaboration. Women would be able to access staff from several agencies in the same place at the same time, and crèche facilities would be easier to arrange. Equally, and perhaps most importantly, women would be treated as 'women' rather than as 'offenders', accessing support in relation to the wider spectrum of issues and difficulties that they face (and, in so doing, reducing their risk of re-offending).

\section{Conclusions}

Once a woman comes to the attention of the police following the reporting of a crime, there is limited scope for discretion amongst professionals and her trajectory through the criminal justice system is all too often inevitable. This trajectory is often underpinned by harsher attitudes towards women who offend, limited opportunities to intervene effectively to address women's wider needs in the context of wider professional and structural constraints, and strict enforcement criteria which leave little room for flexibility. This leads us to two conclusions in particular: first, that earlier intervention is needed to divert women from the criminal justice process and second, that greater emphasis should be placed on the development of multi-faceted welfare services that can better address female offenders' needs.

\section{Earlier intervention}

Our research suggests that there is scope for greater use to be made in Scotland of diversion from prosecution to social work and other support. The use of diversion schemes in Scotland varies dramatically across the eight CJAs, and whilst, as mentioned earlier, Lothian and Borders accounts for 44 per cent of all diversion cases commenced, Glasgow accounts for only 1.1 per cent (Scottish Government, 
2006). However, such schemes have proved successful in diverting individuals for whom prosecution is deemed not to be necessary towards sources of assistance and support (Barry and Mclvor, 2000). In this way, alleged offenders are able to access social work support but without the formality and intrusiveness of a probation order and with a clearer focus on offending-related needs rather than offending behaviour. For women in particular, such proactive intervention without criminalization and associated stigmatization might offer a welcome lifeline in promoting stability and desistance.

At a slightly later point in the criminal justice process, structured deferred sentences - where sentence is deferred by the court for specific social work or other input and then reviewed by the sentencing sheriff at the end of a stipulated period - have been successfully piloted in other parts of Scotland (Macdivitt, 2008). Structured deferred sentences offer the possibility of providing packages of support and intervention without the need for a formal court order. With their primary focus on needs rather than deeds they would appear particularly suited to women offenders. Packages of 'structured' support could include the co-ordination by supervising social workers of multi-agency services delivered where available through community based women's centres ('one-stop-shops'). This work might possibly be supported in appropriate cases by ongoing judicial review as currently occurs in the problem-solving courts that have been introduced in Scotland and other parts of the UK and the wider use of which has been recommended by the recent review of the Prisons Commission in Scotland (Scottish Government, 2008d) as a means of supporting progress and encouraging compliance.

\section{Welfare rather than punishment}

As is evident from much research on women offenders, the needs presented by women who offend are less to do with offending per se and more to do with underlying problems in their lives (Carless, 2006). Factors such as former or current abuse, poverty, difficulties with parenting, substance misuse and abusive relationships may be associated with an increased likelihood of offending (Carless, 2006). It is acknowledged that women involved in the criminal justice system, in particular those incarcerated, have a higher incidence of mental health and other problems than either male offenders or the female population at large (Graham, 2007; Ministry of Justice, 2009; Ogloff and Tye, 2007). Wider problems such as these - both by their nature and their complexity - make it difficult for professionals to work effectively with women solely within the confines of the criminal justice system, not least where standardized group work programmes - developed to address offending by men - are often the norm. Priority must therefore be given to offering practical and emotional help to women in crisis rather than focusing predominantly on their offending behaviour and their ability (or not) to comply with what are often onerous requirements. Offending is, arguably more so for women than men, a reflection of other deep-rooted problems. This being the case, it is unrealistic to expect that the criminal justice system alone can provide effective responses to damaged women leading chaotic lives.

The focus on risk of re-offending and public protection that has gained ascendancy in probation policy and practice in recent years has, arguably, resulted in community-based resources being diverted away from women who offend because women's offending rarely presents a significant public risk (Scottish Office, 1998). Yet if their needs were met earlier, women would, it is argued, be less likely to re-offend. Ironically, perhaps, women who offend fall outwith the politicization agenda currently dominant in the 'law and order debate' precisely because they do not pose a public risk: they are not, as one respondent in the present study suggested, a 'political priority'. This may be slowly changing as female prison 
populations continue to rise and as successive reports highlight the vulnerabilities of women who come into contact with the criminal justice system. If female offenders' needs are to be taken seriously, however, politicians might need to be persuaded of the importance of adopting an holistic rather than a piecemeal approach that recognises a wider social justice agenda.

\section{Notes}

1 There are eight Community Justice Authorities in Scotland, which consist of groupings of local authority criminal justice social work departments, the police, the Crown Office and Procurator Fiscal Service, the NHS, Scottish Court Services, Scottish Prison Service and voluntary sector agencies. Their remit is to oversee criminal justice services in each grouping with the dual aim of reducing reoffending and protecting the public.

2 Cornton Vale is Scotland's only dedicated female prison.

\section{References}

Barry, M. (2007a) Effective Approaches to Risk Assessment in Social Work. Edinburgh: The Scottish Government.

Barry, M. (2007b) Youth Offending in Transition: The Search for Social Recognition. Abingdon: Routledge.

Barry, M. and G. Mclvor (2000) Diversion from Prosecution to Social Work and other Service Agencies. Edinburgh: Scottish Executive.

Barry, M. and G. Mclvor (2008) Chaotic Lives: A Profile of Women Offenders in the Criminal Justice System in Lothian and Borders. Peebles: Lothian and Borders Justice Authority.

Carless, S. (2006) 'Constructive Work with Women Offenders: A Probation in Prison Perspective', in D. Gorman, M. Gregory, M. Hayles and N. Parton (eds) Constructive Work with Offenders. London: Jessica Kingsley Publishers.

Corston, J. (2007) A Review of Women with Particular Vulnerabilities in the Criminal Justice System. London: Home Office.

Gelsthorpe, L. and G. Mclvor (2007) 'Dealing with Difference and Diversity', in L. Gelsthorpe and R. Morgan (eds) Handbook of Probation. Cullompton: Willan Publishing.

Graham, L. (2007) Prison Health in Scotland - A Health Care Needs Assessment. Edinburgh: Scottish Prison Service.

Hedderman, C. (2004) 'Why are More Women being Sentenced to Custody?', in G. Mclvor (ed.) Women who Offend, Research Highlights in Social Work, 44. London: Jessica Kingsley Publishers.

Home Office (2004) Paying the Price: A Consultation Paper on Prostitution. London: Home Office Communication Directorate.

Lothian \& Borders Community Justice Authority (2008) Area Plan 2008-2011. Peebles: Lothian \& Borders CJA.

Loucks, N., M. Malloch, G. Mclvor and L. Gelsthorpe (2006) Evaluation of the 
218 Centre. Edinburgh: Scottish Executive Social Research.

McAra, L. (2008) 'Crime, Criminology and Criminal Justice in Scotland', European Journal of Criminology 5(4): 481-504.

Macdivitt, K. (2008) An Evaluation of the Structured Deferred Sentence Pilots. Edinburgh: Scottish Government.

Mclvor G. (1998) 'Jobs for the Boys?: Gender Differences in Referral for Community Service', The Howard Journal 37(3): 280-91.

Mclvor G. (2004) 'Service with a Smile? Women and Community "punishment"', in G. Mclvor (ed.) Women Who Offend. London: Jessica Kingsley Publishers.

Mclvor, G. (2007) 'The Nature of Female Offending', in R. Sheehan, G. Mclvor and C. Trotter (eds) What Works with Women Offenders, Cullompton: Willan Publishing.

Mclvor, G. (2008) Women and Community Sanctions in Scotland, Paper presented at the European Society of Criminology, Edinburgh.

Mclvor, G. and M. Barry (1998) Social Work and Criminal Justice - Volume 6: Probation. Edinburgh: Stationery Office.

Mclvor, G. and H. Kemshall (2002) Serious Violent and Sexual Offenders: The Use of Risk Assessment Tools in Scotland. Edinburgh: Scottish Executive.

Malloch, M., G. Mclvor and N. Loucks (2008) "Time Out" for Women: Innovation in Scotland in a Context of Change', The Howard Journal 47(4): 383-99.

Maurutto, P. and K. Hannah-Moffat (2006) 'Assembling Risk and the Restructuring of Penal Control', British Journal of Criminology 46(3): 438-54.

Ministry of Justice (2009) Statistics on Women and the Criminal Justice System. London: Ministry of Justice.

Ministry of Justice/NOMS (2008) National Service Framework: Improving Services to Women Offenders. London: MOJ/NOMS.

Morgan, R. (2009) 'Children and Young People: Criminalization and Punishment', in M. Barry and F. McNeill (eds) Youth Offending and Youth Justice. London: Jessica Kingsley Publishers.

Ogloff, J. and C. Tye (2007) 'Responding to Mental Health Needs of Women Offenders', in R. Sheehan, G. Mclvor and C. Trotter (eds) What Works with Women Offenders. Cullompton: Willan Publishing.

Scottish Government (2006) Diversion from Prosecution by CJA. URL (accessed 18 May 2009): http://www.scotland.gov.uk/Topics/Statistics/Browse/Crime-Justice/ DPCJA

Scottish Government (2007) Criminal Justice Social Work Statistics 2006-7. Edinburgh: Scottish Government

Scottish Government (2008a) Prison Statistics Scotland 2007/8. Edinburgh: Scottish Government. 
Scottish Government (2008b) Criminal Proceedings in Scottish Courts 2006/7. Edinburgh: Scottish Government.

Scottish Government (2008c) Criminal Justice Social Work Statistics 2007-8. Edinburgh: Scottish Government.

Scottish Government (2008d) Scotland's Choice: Report of the Scottish Prisons Commission. Edinburgh: Scottish Government.

Scottish Offi ce (1998) Women Offenders: A Safer Way. Edinburgh: Scottish Offi ce. Sheehan, R., G. Mclvor and C. Trotter (2007) 'Introduction', in R. Sheehan, G. Mclvor and C. Trotter (eds) What Works with Women Offenders. Cullompton: Willan Publishing. 